\title{
An Unusual Case of Gastrointestinal Bleeding in Metastatic Renal Cell Carcinoma
}

\author{
Niamh Peters ${ }^{a} \quad$ Clara Lightner $^{b} \quad$ John McCaffrey ${ }^{a}$ \\ aDepartment of Medical Oncology, Mater Misercordiae University Hospital, Dublin 7, Ireland; \\ bDepartment of Histopathology, Mater Misercordiae University Hospital, Dublin 7, Ireland
}

\section{Keywords}

Small intestine metastases $\cdot$ Renal cell cancer

\begin{abstract}
Approximately 340 patients are diagnosed with renal cell cancer (RCC) in Ireland each year. Metastatic spread to the lung, lymph nodes and bones is common. Metastatic spread to the gastrointestinal tract, including the small bowel, is a rare phenomenon. Therapeutic advances have led to an improved overall survival in RCC and, as a result, unusual sites of metastatic spread are becoming more common. We present the case of a 68-year-old gentleman presenting with upper gastrointestinal bleeding as a result of metastases to the duodenum from renal cell carcinoma.

\section{Introduction}

Approximately 340 new cases of renal cell cancer (RCC) are diagnosed each year in Ireland [1]. The most common sites of RCC metastases are the lung, lymph nodes, liver and bones [2]. RCC metastasising to the small bowel is considered uncommon, with duodenal involvement particularly rare. There are less than 40 cases reported in the English language literature to date. With the advent of newer treatment strategies and the resulting improved survival, the incidence of gastrointestinal metastatic disease will become more common [3]. We present a case of metastatic RCC to the duodenum which was seen recently at our institution. Full consent was obtained from the patient and his family following review of the manuscript and associated images. 


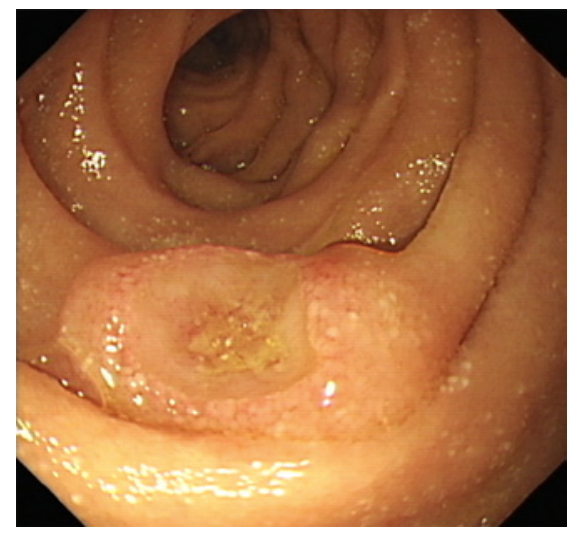

Fig. 1. A polypoid lesion visible in the second segment of the duodenum.

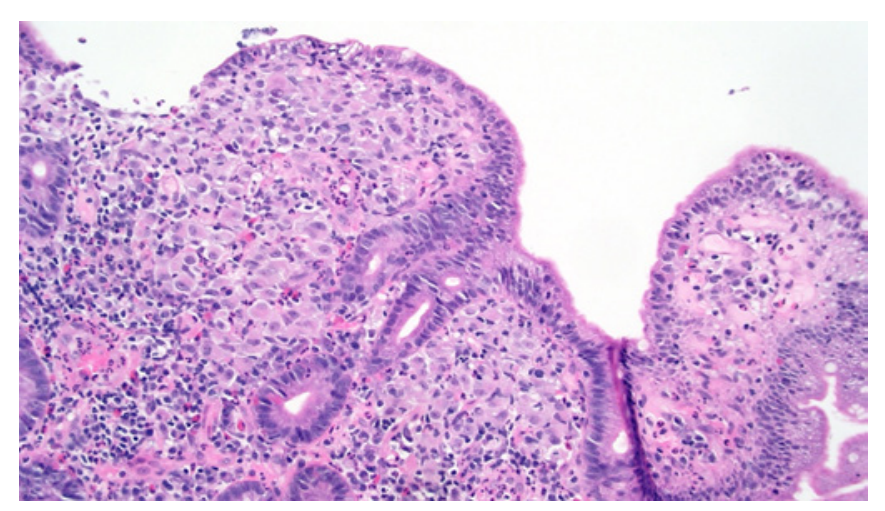

Fig. 2. Tumour cells infiltrate and expand the lamina propria of the duodenal villi.

\section{Case Report}

A 68-year-old gentleman presented to the Emergency Department with a 2-day history of worsening shortness of breath, fatigue and melena. He had been diagnosed with renal cell carcinoma with metastases to the bones, liver and lymph nodes 18 months previously. He was undergoing second-line treatment with nivolumab and recent imaging had demonstrated a partial response to treatment. Of note, his medications included therapeutic anticoagulation for a previous pulmonary embolus.

Routine blood tests demonstrated a haemoglobin level of $6.5 \mathrm{~g} / \mathrm{dL}$, a considerable decline from his baseline level of $11.8 \mathrm{~g} / \mathrm{dL}$ a week prior to presentation. His faecal occult blood was positive. His anticoagulation was held, and he was transfused two units of red blood cells. He proceeded to urgent oesophago-gastro duodenoscopy, which demonstrated a polypoid lesion in the second segment of the duodenum (Fig. 1).

Duodenal biopsies demonstrated variable mucosal and submucosal infiltration by carcinoma with an epithelioid morphology and areas of prominent cytoplasmic clearing. This was in keeping with his metastatic renal cell carcinoma (Fig. 2).

Due to ongoing bleeding, the decision was taken to embolise the tumour under radiological guidance. This proved successful and the patient's haemoglobin level stabilised. Restaging computed topography (CT) revealed the development of pulmonary metastases and rapid progression of existing sites of disease. As his performance status remained satisfactory, his systemic treatment was changed to a third-generation tyrosine kinase inhibitor axitinib.

\section{Discussion}

A recent cohort study of over 3,000 patients described the prevalence of symptomatic small intestinal metastases from RCC as $0.71 \%$, although post mortem studies have found a higher incidence at $2 \%[4,5]$. The ileum is the most common site of disease, with duodenal metastases from RCC being a much rarer phenomenon $[3,5]$.

Metastases can be a result of direct infiltration, lymphatic or haematogenous spread [5].

Owing to the vascular nature of RCC, those with duodenal metastases most commonly present with acute or chronic upper gastrointestinal bleeding. This is of particular concern given a significant number of these patients require anticoagulation for malignancy-related 
Peters et al:

thromboembolic events [6]. Additionally, cases of obstruction, perforation, intussusception and obstructive jaundice secondary to duodenal metastases from RCC have been reported [7]. On direct visualisation by endoscopy lesions are mostly solitary, polypoid or ulcerated submucosal masses [4].

There is no standard management for duodenal metastases with an individualised approach recommended. In fit patients, with a solitary duodenal RCC metastasis, complete surgical resection should be considered. In those with widespread disease, palliative approaches include palliative surgery, embolisation, radiotherapy or systemic treatment [8].

\section{Conclusion}

Metastatic spread to the duodenum by RCC should be considered in patients with RCC presenting with signs or symptoms of upper gastrointestinal bleeding, iron deficiency anaemia or unexplained gastrointestinal symptoms.

\section{Acknowledgement}

Dr. Niamh Peters, Dr. Clara Lightner and Prof. John McCaffrey were the only contributors to this article.

\section{Statement of Ethics}

Full consent was obtained from the patient and his family following review of the manuscript and associated images.

\section{Disclosure Statement}

The authors have no conflicts of interest to declare.

\section{Funding Sources}

No funding was received for the writing of this article.

\section{Author Contributions}

All three authors were involved in the conception of this case report, have helped draft the manuscript and have approved it for publication. Additionally, Dr. Lightner supplied the histological figure and Dr. Peters supplied the oesophago-gastro duodenoscopy figure. All authors are in agreement to be accountable for all aspects of this work. 


\section{References}

1 Ncri.ie. 2019 [cited 2019 Jul 15]. Available from: https://www.ncri.ie/sites/ncri/files/pubs/ CancerTrendsNo.11-CancersoftheKidneyUreterandBladder.pdf

2 Bianchi M, Sun M, Jeldres C, Shariat S, Trinh Q, Briganti A, et al. Distribution of metastatic sites in renal cell carcinoma: a population-based analysis. Ann Oncol. 2011;23(4):973-80.

3 Mueller J, Guyer R, Adler J, Mullen J. Metastatic renal cell carcinoma to the small bowel: three cases of GI bleeding and a literature review. CEN Case Rep. 2017;7(1):39-43.

4 Park H, Kim H, Park S, Lee J, Kim A, Ha H. Gastrointestinal Involvement of Recurrent Renal Cell Carcinoma: CT Findings and Clinicopathologic Features. Korean J Radiol. 2017;18(3):452.

5 Willis RA. The spread of tumours in the human body. London: Butterworth \& Co Ltd; 1973. Vol. 3. Secondary tumors of the intestines; pp. 209-15.

6 Lee A. Venous Thromboembolism and Cancer: Risks and Outcomes. Circulation. 2003;107(23 Suppl1):I17-21.

7 Omranipour R, Mahmoud Zadeh H, Ensani F, Yadegari S, Miri SR. Duodenal metastases from renal cell carcinoma presented with melena: review and case report. Iran J Pathol. 2017;12(3):272-6.

8 Rustagi T, Rangasamy P, Versland M. Duodenal bleeding from metastatic renal cell carcinoma. Case Rep Gastroenterol. 2011;5(1):249-57. 